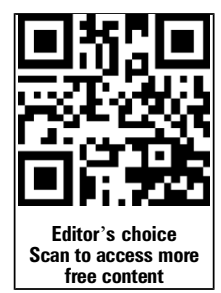

- Additional material is published online only. To view please visit the journal online (http://dx.doi.org/10.1136/ heartjnl-2015-308742).

Institut Universitaire de Cardiologie et de Pneumologie de Québec/Québec Heart \& Lung Institute, Laval University, Québec City, Québec, Canada

Correspondence to Dr Philippe Pibarot, Institut Universitaire de Cardiologie et de Pneumologie de Québec, 2725 Chemin Sainte-Foy, Québec City, Québec, Canada G1V-4G5; philippe.pibarot@med.ulaval.ca

Received 28 September 2015 Revised 24 February 2016 Accepted 25 February 2016 Published Online First 5 April 2016

\title{
Echocardiographic predictors of outcomes in adults with aortic stenosis
}

\author{
Romain Capoulade, Florent Le Ven, Marie-Annick Clavel, Jean G Dumesnil, \\ Abdellaziz Dahou, Christophe Thébault, Marie Arsenault, Kim O'Connor, \\ Élisabeth Bédard, Jonathan Beaudoin, Mario Sénéchal, Mathieu Bernier, \\ Philippe Pibarot
}

\begin{abstract}
Objective The study purpose was to assess the usefulness of echocardiographic parameters of aortic stenosis (AS) severity and left ventricular (LV) systolic function to predict mortality in AS. The main hypothesis is that parameters of LV systolic function are the most important independent predictors of mortality, whereas parameters of stenosis severity are not.

Methods 1065 consecutive patients with AS referred to the echocardiography laboratory and meeting the inclusion/exclusion criteria were included and followed during 5.7 years. The end points were aortic valve replacement (AVR) $(n=584)$, composite of AVR or death $(n=932)$, all-cause mortality $(n=550)$ and cardiovascular mortality ( $n=398)$.
\end{abstract}

Results The most powerful echocardiographic predictors of valve-related events were parameters of AS severity, such as peak aortic jet velocity $\left(\mathrm{V}_{\text {Peak }}\right)$, mean gradient (MG) and aortic valve area (AVA) (all $p<0.001$ ). Regarding mortality, the main predictors were LV ejection fraction (LVEF) and stroke volume index (SVi) $(p<0.05)$. After multivariable adjustment, LVEF $(p<0.001)$ and SVi $(p=0.02)$ remained the only echocardiographic predictors of mortality, even after adjustment for symptomatic status. AVA was also associated with mortality, whereas $V_{\text {Peak }}$ and MG were not.

Conclusions The most powerful echocardiographic predictors of mortality are low LVEF and low flow, whereas AS severity parameters predict valve-related events but not overall mortality. Hence, low flow should be integrated in the risk stratification and therapeutic decision-making in patients with AS.

\section{INTRODUCTION}

The 2012 European Society of Cardiology/ European Association of Cardio-Thoracic Surgery and 2014 American College of Cardiology/ American Heart Association guidelines propose to use the following echocardiographic parameters and criteria to define severe aortic stenosis (AS): peak aortic jet velocity $\left(\mathrm{V}_{\text {Peak }}\right) \geq 4 \mathrm{~m} / \mathrm{s}$, mean gradient $(\mathrm{MG}) \geq 40 \mathrm{~mm} \mathrm{Hg}$ and aortic valve area (AVA) $\leq 1 \mathrm{~cm}^{2} .{ }^{2}{ }^{2}$ Furthermore, these guidelines recommend aortic valve replacement (AVR) when the stenosis is severe and the patient develops symptoms and/or left ventricular (LV) systolic dysfunction, which is defined as LV ejection fraction (LVEF) $<50 \% .^{12}$ The vast majority of the outcome studies, on which these recommendations are based, used the composite end point of AVR or death, which is largely driven by AVR. ${ }^{3-7}$ These studies reported that parameters of AS severity, such as $\mathrm{V}_{\text {Peak }}$ or $\mathrm{MG}$, are the most powerful independent predictors of these events. However, very few studies examined the association between echocardiographic parameters and more robust end points such as overall mortality, and these studies suggested that AVA may be superior to $\mathrm{V}_{\text {Peak }}$ or MG to predict this end point. ${ }^{8}$

Several studies reported that a significant proportion of patients may present with discrepancies among echocardiographic parameters with respect to the grading of AS severity: that is, $\mathrm{MG}<40 \mathrm{~mm} \mathrm{Hg}$ but AVA $<1 \mathrm{~cm}^{2} .^{9-12}$ And as a consequence, some investigators proposed to lower the cut-point value (CPV) of AVA to define severe AS down to $0.8 \mathrm{~cm}^{2} \cdot{ }^{11}{ }^{12}$ In recent studies, a low flow state, defined as a LV stroke volume index (SVi) $<35 \mathrm{~mL} / \mathrm{m}^{2}$, is associated with worse outcomes in both patients with low LVEF (classical low flow) and those with preserved LVEF (paradoxical low flow). ${ }^{9}$ 13-16

The main objective of this study was thus to determine which echocardiographic parameters and CPVs best predict clinical outcomes including the need for AVR, all-cause mortality and cardiovascular (CV) mortality in a large 'real-life' cohort of patients representative of the clinical spectrum of AS. We hypothesised that (i) echocardiographic parameters of stenosis severity are the most powerful predictors of valve-related events, whereas parameters of LV function are the most powerful predictors of mortality; (ii) the CPV $\left(<1.0 \mathrm{~cm}^{2}\right)$ of AVA proposed in the current guidelines to define severe AS and predict outcomes is appropriate; (iii) the CPV of LVEF proposed in the guidelines $(<50 \%)$ to identify LV systolic dysfunction and recommend AVR is too low and (iv) the CPV $\left(<35 \mathrm{~mL} / \mathrm{m}^{2}\right)$ of SVi proposed in the current guidelines to low flow AS and predict outcomes is appropriate.

\section{METHODS}

\section{Patient population}

We retrospectively analysed the clinical and Doppler echocardiographic data that were prospectively collected in consecutive patients with at least mild AS ( $\left.\mathrm{V}_{\text {Peak }}>2.0 \mathrm{~m} / \mathrm{s}\right)$ who underwent an 
echocardiographic exam at the Québec Heart and Lung Institute between 1999 and 2007. Patients were excluded if they presented the following criteria: (i) $\geq$ moderate aortic regurgitation, (ii) $\geq$ moderate mitral stenosis or regurgitation, (iii) previous valve intervention or (iv) incomplete clinical and/or Doppler echocardiographic data. According to these criteria, 1065 patients were finally included in this study and the baseline clinical and echocardiographic data were prospectively collected but retrospectively queried. The follow-up time was calculated from the baseline echocardiography to the occurrence of event or last clinical follow-up. In total, 523 patients were included in some of our previous studies. ${ }^{13}{ }^{17}$ However, the sample size, the duration of follow-up and the number of events are much higher and the focus is different in the present study versus in the previous ones.

\section{Clinical data}

Clinical data included age, gender, height, weight, body surface area, systolic and diastolic blood pressure and symptomatic status. Clinical comorbidities were documented by review of medical chart and included hypertension (patients receiving antihypertensive medications or having known but untreated hypertension (blood pressure $\geq 140 / 90 \mathrm{~mm} \mathrm{Hg}$ ), diabetes (patients receiving oral hypoglycaemic or insulin medications or, in the absence of such medications, having a fasting glucose $\geq 7 \mathrm{mmol} / \mathrm{L}$ ), coronary artery disease (history of myocardial infarction, significant coronary artery stenosis (ie, $>50 \%$ ) on coronary angiography and/or regional wall motion abnormality on echocardiogram), atrial fibrillation, chronic obstructive pulmonary disease and renal failure (estimated glomerular filtration rate $\left.<60 \mathrm{~mL} / \mathrm{min} / 1.73 \mathrm{~m}^{2}\right)$ ).

\section{Doppler echocardiographic data}

All patients underwent a comprehensive Doppler echocardiographic exam with a commercially available ultrasound system. All Doppler echocardiographic exams were performed and analysed in the same laboratory by the same team of sonographers and cardiologists.

LVEF was calculated with the biplane Simpson method. Stroke volume was calculated by multiplying the LV outflow tract area by the flow velocity-time integral and was indexed to body surface area $(\mathrm{SVi})$. The haemodynamic parameters of AS severity included (i) peak aortic jet velocity $\left(\mathrm{V}_{\text {Peak }}\right)$, (ii) mean transvalvular pressure gradient (MG), (iii) AVA calculated by the standard continuity equation, (iv) AVA indexed to body surface area (AVAi), (v) energy loss index (ELI) as previously published ${ }^{18}$ and (vi) dimensionless velocity index (DVI). ${ }^{19} \mathrm{~A}$ multiwindow interrogation including apical five-chamber and three-chamber, right parasternal and suprasternal with standard and ped-off probes was systematically done. In patients with atrial fibrillation, measurements were calculated as the average of five cycles with least variation of $\mathrm{R}-\mathrm{R}$ intervals and as close as possible to normal heart rate. ${ }^{19}$ The degree of aortic, mitral and tricuspid regurgitation was classified according to the recommendations of the European Association of Cardiovascular Imaging. ${ }^{20}$ The valvuloarterial impedance $\left(\mathrm{Z}_{\mathrm{va}}\right)$ was also calculated. ${ }^{17}$

\section{Study end points}

The study end points were the occurrence of (i) all-cause mortality, (ii) CV mortality, (iii) the composite end point of AVR or all-cause death, and (iv) AVR alone. The last update of the clinical events was obtained from Quebec National Institute of Statistics in January 2013.

\section{Statistical analysis}

Continuous data were expressed as mean $\pm \mathrm{SD}$ or median (IQR). The continuous variables were tested for normality of distribution and homogeneity of variances with the Shapiro-Wilk and Levene tests, respectively. Categorical data were expressed as percentage and compared with the $\chi^{2}$ test or Fischer's exact test when appropriate.

Kaplan-Meier curves and log-rank tests of the time-to-event data were used to assess the effect of the clinical and echocardiographic factors on outcomes. Multivariable Cox proportional hazard analyses were used to identify the independent association between these factors and outcomes. The proportionalhazards assumption was checked with the use of Schoenfeld residuals. Age, gender and the variables with a $\mathrm{p}$ value $<0.10$ in univariable analysis for the given end point were entered into the multivariable Cox models. To prevent collinearity, we avoided to include in the same model variables (ie, parameters of AS severity) that were strongly correlated. The impact of AVR on all-cause and CV mortality was analysed in multivariable Cox models with the use of AVR entered as a time-dependent variable.

Receiver operating characteristic (ROC) curve analyses were performed to determine the ability of the Doppler echocardiographic parameters $\left(\mathrm{V}_{\text {Peak }}, \mathrm{MG}, \mathrm{AVA}, \mathrm{AVAi}, \mathrm{ELI}, \mathrm{DVI}, \mathrm{Z}_{\mathrm{va}}, \mathrm{SV}\right.$, LVEF) to discriminate between patients with and without events (area under the curve) as well as the CPVs providing the highest Youden index (sensitivity +specificity -1 ) to predict outcomes at 1-year follow-up. A p value $<0.05$ was considered statistically significant.

\section{RESULTS}

\section{Patient characteristics}

The baseline characteristics of 1065 patients included in this study are presented in table 1 . Among these patients, 53\% $(n=565)$ had severe AS, $34 \%$ had a low flow state, that is, SVi $<35 \mathrm{~mL} / \mathrm{m}^{2}$, and $17 \%$ had a LVEF $<50 \%$ (table 1). The median follow-up in this cohort was 5.7 years (IQR 1.9-8.4). Among the 919 patients (86\% of the whole cohort) with evaluation of symptomatic status, 77\% presented symptoms (New York Heart Association (NYHA) class $\geq 2$; table 1 and online supplementary table S1). Patients with symptoms had worse risk profile as well as more severe AS and lower LVEF and SVi at baseline compared with asymptomatic patients (see online supplementary table S1).

\section{Echocardiographic predictors of AVR and of the composite of AVR or death}

During the follow-up, 584 patients underwent AVR (including 35 transcatheter AVRs) and 932 patients reached the composite end point of AVR or death (table 2). In univariable analysis, parameters of AS severity (ie, $\mathrm{V}_{\text {Peak }}$, MG, AVA, AVAi, ELI and DVI) were strongly associated with the occurrence of the composite end point of AVR or death (all $\mathrm{p}<0.001$; table 2). Parameters of LV systolic function (ie, LVEF and $S V i$ ) and $Z_{v a}$ were also associated with this end point $(\mathrm{p} \leq 0.03$; table 2$)$. After multivariable adjustment (table 2$), M G(p<0.001)$ and LVEF $(\mathrm{p}=0.02)$ remained independently associated with the composite end point of AVR or death, whereas SVi did not $(p=0.26)$. After the substitution of SVi and MG by $Z_{\mathrm{va}}$, the latter was an independent predictor of the composite end point of AVR or death $(\mathrm{HR}=1.24,95 \% \mathrm{CI} 1.16$ to $1.32, \mathrm{p}<0.001)$.

The association between AS severity parameters and valve-related events was confirmed in several complementary analyses: (i) analysis in the whole cohort but with the use of 
Table 1 Patients characteristics $(n=1065)$

\begin{tabular}{|c|c|}
\hline \multicolumn{2}{|l|}{ Clinical data } \\
\hline Age, years & $71 \pm 13$ \\
\hline Male gender, \% & 58 \\
\hline Height, cm & $165 \pm 10$ \\
\hline Weight, kg & $75 \pm 16$ \\
\hline Body surface area, $\mathrm{m}^{2}$ & $1.8 \pm 0.2$ \\
\hline Body mass index, $\mathrm{kg} / \mathrm{m}^{2}$ & $27 \pm 5$ \\
\hline Symptoms ( $n=919), \%$ & 77 \\
\hline History of hypertension, \% & 72 \\
\hline Systolic blood pressure, mm Hg & $132 \pm 22$ \\
\hline Diastolic blood pressure, $\mathrm{mm} \mathrm{Hg}$ & $72 \pm 11$ \\
\hline Diabetes, \% & 27 \\
\hline Coronary artery disease, $\%$ & 57 \\
\hline Prior myocardial infarction, \% & 31 \\
\hline Atrial fibrillation, $\%$ & 8 \\
\hline Chronic obstructive pulmonary disease, \% & 21 \\
\hline Renal failure, \% & 18 \\
\hline Logistic EuroSCORE, \% & $7.1(3.7-14.9)$ \\
\hline \multicolumn{2}{|l|}{ Doppler echocardiographic data } \\
\hline \multicolumn{2}{|l|}{ Standard echo variables } \\
\hline Bicuspid aortic valve, $\%$ & 27 \\
\hline LV outflow tract diameter, $\mathrm{cm}$ & $2.1 \pm 0.2$ \\
\hline Stroke volume index, $\mathrm{mL} / \mathrm{m}^{2}$ & $39 \pm 9$ \\
\hline Peak aortic jet velocity, $\mathrm{m} / \mathrm{s}$ & $3.3 \pm 0.9$ \\
\hline Mean transvalvular gradient, $\mathrm{mm} \mathrm{Hg}$ & $27 \pm 16$ \\
\hline Aortic valve area, $\mathrm{cm}^{2}$ & $1.00 \pm 0.31$ \\
\hline Aortic valve area index, $\mathrm{cm}^{2} / \mathrm{m}^{2}$ & $0.56 \pm 0.18$ \\
\hline Energy loss index, $\mathrm{cm}^{2} / \mathrm{m}^{2}$ & $0.65 \pm 0.24$ \\
\hline Dimensionless velocity index & $0.29 \pm 0.09$ \\
\hline Aortic regurgitation grade & $1(0-1)$ \\
\hline Mitral regurgitation grade & $1(0-2)$ \\
\hline Tricuspid regurgitation grade & $1(0-2)$ \\
\hline LV ejection fraction, \% & $60 \pm 14$ \\
\hline LV end-diastolic diameter, cm & $4.8 \pm 0.7$ \\
\hline LV end-systolic diameter, cm & $3.0 \pm 0.8$ \\
\hline LV end-diastolic volume, $\mathrm{mL}$ & $111 \pm 36$ \\
\hline Valvuloarterial impedance, $\mathrm{mm} \mathrm{Hg} / \mathrm{mL} \mathrm{m}^{2}$ & $4.2 \pm 1.2$ \\
\hline \multicolumn{2}{|c|}{ Prevalence of patients according to threshold values defined by guidelines } \\
\hline Stroke volume index $<35 \mathrm{~mL} / \mathrm{m}^{2}, \%$ & 34 \\
\hline Peak aortic jet velocity $>4 \mathrm{~m} / \mathrm{s}, \%$ & 22 \\
\hline Mean transvalvular gradient $>40 \mathrm{~mm} \mathrm{Hg} \%$ & 19 \\
\hline Aortic valve area $<1 \mathrm{~cm}^{2}, \%$ & 51 \\
\hline Aortic valve area index $<0.6 \mathrm{~cm}^{2} / \mathrm{m}^{2}, \%$ & 62 \\
\hline Energy loss index $<0.6 \mathrm{~cm}^{2} / \mathrm{m}^{2}, \%$ & 46 \\
\hline Dimensionless velocity index $<0.25, \%$ & 41 \\
\hline LV ejection fraction $<50 \%, \%$ & 17 \\
\hline Valvuloarterial impedance $>4.5, \%$ & 35 \\
\hline
\end{tabular}

AVR alone as the end point (all $\mathrm{p}<0.001$; table 2); (ii) subanalysis in the subset of patients with severe AS $(n=565$; all $\mathrm{p}<0.001$; see online supplementary table 2); (iii) analysis with further adjustment for symptomatic status $(n=919 ; \mathrm{p}<0.001$; see online supplementary table 3 ) and (iv) inclusion of $V_{\text {Peak }}$, AVA or AVAi, instead of MG in the multivariable models (all $\mathrm{p}<0.001$; data not shown).

The best CPVs of the stenosis severity parameters to predict valve-related events at 1 year $(n=394$ composite end point of AVR or death and $n=310$ AVRs alone) were $3.5 \mathrm{~m} / \mathrm{s}$ for $\mathrm{V}_{\text {Peak }}$ (figure $1 \mathrm{~A}$ ) and $31 \mathrm{~mm} \mathrm{Hg}$ for $\mathrm{MG}$ (figure $1 \mathrm{~B}$ ), whereas those for AVA, AVAi, ELI and DVI were $1.01 \mathrm{~cm}^{2}$ (figure 1C), $0.55 \mathrm{~cm}^{2} / \mathrm{m}^{2}, 0.59 \mathrm{~cm}^{2} / \mathrm{m}^{2}$ and 0.27 , respectively (see online supplementary table $\mathrm{S} 4) . \mathrm{Z}_{\mathrm{va}}$ was also associated with these end points $(\mathrm{p}<0.001)$, and the best $\mathrm{CPV}$ was $4.4 \mathrm{~mm} \mathrm{Hg} / \mathrm{mL} \mathrm{m}^{2}$ (see online supplementary table S4).

\section{Echocardiographic predictors of all-cause and CV mortality}

During the follow-up, 550 patients died and 398 of these deaths were of CV cause (table 3). Among these 550 deaths, 348 (63\%) occurred before AVR and the remaining 202 (37\%) after AVR. In univariable analysis, parameters of LV systolic function (ie, LVEF and $\mathrm{SVi}$ ) were significantly associated with all-cause mortality (all $\mathrm{p}<0.001$; table 3). Among parameters of AS severity, smaller AVA and lower $V_{\text {Peak }}$ and $M G$ were significantly associated with increased risk of all-cause mortality (all $\mathrm{p} \leq 0.005$; table 3 ). $\mathrm{Z}_{\mathrm{va}}$ was also associated with all-cause mortality $(\mathrm{p}<0.001)$. After multivariable adjustment (table 3$)$, SVi $(\mathrm{p}=0.02)$ and LVEF $(\mathrm{p}<0.001)$ were independently associated with all-cause mortality, whereas MG or other parameter of stenosis severity was not $(p=0.81)$. Further adjustment for AVR as a time-dependent variable provided similar results: that is, $\mathrm{LV}$ systolic function parameters (all $\mathrm{p}<0.05$ ) remained powerful predictor of all-cause mortality and AVR was strongly associated with improved survival $(\mathrm{HR}=0.59,95 \% \mathrm{CI}$ 0.47 to $0.75, \mathrm{p}<0.001)$. After the substitution of SVi and MG by $\mathrm{Z}_{\mathrm{va}}$, the latter was an independent predictor of all-cause mortality $(\mathrm{HR}=1.10,95 \%$ CI 1.00 to $1.20, \mathrm{p}=0.045)$.

The association between LV systolic function parameters (ie, LVEF and SVi) and all-cause mortality was confirmed in several complementary analyses: (i) analysis with CV mortality as the end point (all $\mathrm{p}<0.05$; table 3 ); (ii) subanalysis in the subset of patients with severe AS ( $n=565$; all $p \leq 0.03$ except for SVi (trend: $p=0.14$ ) to predict CV mortality; see online supplementary table S5); (iii) subanalysis for mortality under medical treatment, that is, patients were censored at the time of AVR (all p $<0.05$ except for SVi (trend: $\mathrm{p}=0.13$ ) to predict all-cause mortality; see online supplementary table S6); (iv) further adjustment for symptomatic status $(n=919$; all $\mathrm{p} \leq 0.03$; see online supplementary table $\mathrm{S} 7)$; (v) inclusion of $\mathrm{V}_{\text {Peak }}$, AVA or AVAi, instead of MG (all $\mathrm{p} \leq 0.03$, data not shown); and (vi) further adjustment for EuroSCORE or tricuspid regurgitation grade $\geq 3$ (all $\mathrm{p}<0.05$, data not shown).

The best CPVs of the parameters of LV systolic/pump function to predict all-cause mortality at 1 year ( $n=114$ deaths) were $56 \%$ for LVEF and $34 \mathrm{~mL} / \mathrm{m}^{2}$ for SVi (see online supplementary table S4). The best CPV for AVA was $1.01 \mathrm{~cm}^{2}$. Analysis of CV mortality provided similar results (see online supplementary table S4). Using the best CPV identified by ROC curve analyses, patients with $\mathrm{SVi}<35 \mathrm{~mL} / \mathrm{m}^{2}$ had significantly higher risk of allcause mortality and CV mortality compared with patients with $\mathrm{SVi}>35 \mathrm{~mL} / \mathrm{m}^{2}$, in both patients with LVEF $<55 \%$ and those with $L V E F \geq 55 \%(p<0.001$; figure $2 A, B)$.

\section{Predictors of outcomes in the subset of patients with asymptomatic AS}

During the median follow-up of 7.4 years (IQR 4.2-9.2), 119 patients of the 212 who were asymptomatic at baseline (ie, defined as NYHA class I) underwent AVR and 175 reached the composite end point of AVR or death (see online supplementary table S8). In multivariable analysis, MG (all p<0.001) remained the most powerful echocardiographic predictor of these outcomes (see online supplementary table S8).

Moreover, during the follow-up, 81 of the 212 patients being asymptomatic at baseline (ie, define as NYHA class I) died and 57 of these deaths were of CV cause (see online supplementary 
Table 2 Predictors of the composite of aortic valve replacement (AVR) or death and AVR alone

\begin{tabular}{|c|c|c|c|c|c|c|c|c|}
\hline \multirow[b]{3}{*}{ Baseline variables } & \multicolumn{4}{|c|}{$\begin{array}{l}\text { AVR or death } \\
n=932 \text { AVR or death }(88 \%)\end{array}$} & \multicolumn{4}{|c|}{$\begin{array}{l}\text { AVR } \\
n=584 \text { AVR }(55 \%)\end{array}$} \\
\hline & \multicolumn{2}{|l|}{ Univariable } & \multicolumn{2}{|l|}{ Multivariable } & \multicolumn{2}{|l|}{ Univariable } & \multicolumn{2}{|l|}{ Multivariable } \\
\hline & $\begin{array}{l}\mathrm{HR} \\
\mathbf{9 5 \%} \mathrm{Cl}\end{array}$ & $p$ Value & $\begin{array}{l}\text { HR } \\
95 \% \mathrm{Cl}\end{array}$ & $\mathrm{p}$ Value & $\begin{array}{l}\text { HR } \\
95 \% \mathrm{Cl}\end{array}$ & $p$ Value & $\begin{array}{l}\mathrm{HR} \\
95 \% \mathrm{Cl}\end{array}$ & $\mathrm{p}$ Value \\
\hline $\begin{array}{l}\text { Age, years } \\
\text { (per } 10 \text { years increase) }\end{array}$ & $\begin{array}{l}1.13 \\
1.07 \text { to } 1.18\end{array}$ & $<0.001$ & $\begin{array}{l}1.11 \\
1.05 \text { to } 1.18\end{array}$ & $<0.001$ & $\begin{array}{l}0.91 \\
0.86 \text { to } 0.96\end{array}$ & $<0.001$ & $\begin{array}{l}0.99 \\
0.94 \text { to } 1.05\end{array}$ & 0.81 \\
\hline Male gender & $\begin{array}{l}1.32 \\
1.15 \text { to } 1.50\end{array}$ & $<0.001$ & $\begin{array}{l}1.29 \\
1.07 \text { to } 1.54\end{array}$ & 0.006 & $\begin{array}{l}1.57 \\
1.33 \text { to } 1.87\end{array}$ & $<0.001$ & $\begin{array}{l}1.08 \\
0.86 \text { to } 1.35\end{array}$ & 0.51 \\
\hline Body surface area, $\mathrm{m}^{2}$ & $\begin{array}{l}1.51 \\
1.12 \text { to } 2.04\end{array}$ & 0.006 & $\begin{array}{l}1.16 \\
0.78 \text { to } 1.72\end{array}$ & 0.47 & $\begin{array}{l}2.80 \\
1.93 \text { to } 4.06\end{array}$ & $<0.001$ & $\begin{array}{l}2.30 \\
1.43 \text { to } 3.69\end{array}$ & 0.001 \\
\hline Hypertension & $\begin{array}{l}1.24 \\
1.08 \text { to } 1.44\end{array}$ & 0.003 & $\begin{array}{l}1.21 \\
1.04 \text { to } 1.42\end{array}$ & 0.02 & $\begin{array}{l}0.97 \\
0.81 \text { to } 1.16\end{array}$ & 0.73 & - & - \\
\hline Diabetes & $\begin{array}{l}1.25 \\
1.09 \text { to } 1.45\end{array}$ & 0.002 & $\begin{array}{l}1.20 \\
1.03 \text { to } 1.40\end{array}$ & 0.02 & $\begin{array}{l}1.12 \\
0.93 \text { to } 1.35\end{array}$ & 0.22 & - & - \\
\hline Coronary artery disease & $\begin{array}{l}1.47 \\
1.29 \text { to } 1.68\end{array}$ & $<0.001$ & $\begin{array}{l}1.21 \\
1.05 \text { to } 1.40\end{array}$ & 0.01 & $\begin{array}{l}1.33 \\
1.13 \text { to } 1.57\end{array}$ & 0.001 & $\begin{array}{l}1.43 \\
1.20 \text { to } 1.70\end{array}$ & $<0.001$ \\
\hline Chronic obstructive pulmonary disease & $\begin{array}{l}1.30 \\
1.11 \text { to } 1.52\end{array}$ & 0.001 & $\begin{array}{l}1.09 \\
0.93 \text { to } 1.29\end{array}$ & 0.29 & $\begin{array}{l}0.83 \\
0.67 \text { to } 1.04\end{array}$ & 0.10 & $\begin{array}{l}0.87 \\
0.67 \text { to } 1.06\end{array}$ & 0.15 \\
\hline Renal failure & $\begin{array}{l}1.67 \\
1.41 \text { to } 1.97\end{array}$ & $<0.001$ & $\begin{array}{l}1.45 \\
1.21 \text { to } 1.73\end{array}$ & $<0.001$ & $\begin{array}{l}1.02 \\
0.80 \text { to } 1.29\end{array}$ & 0.90 & - & - \\
\hline $\begin{array}{l}\text { Stroke volume index, } \mathrm{mL} / \mathrm{m}^{2} \\
\text { (per } 5 \mathrm{~mL} / \mathrm{m}^{2} \text { decrease) }\end{array}$ & $\begin{array}{l}1.04 \\
1.00 \text { to } 1.08\end{array}$ & 0.03 & $\begin{array}{l}1.03 \\
0.98 \text { to } 1.07\end{array}$ & 0.26 & $\begin{array}{l}0.96 \\
0.92 \text { to } 1.01\end{array}$ & 0.08 & $\begin{array}{l}1.01 \\
0.96 \text { to } 1.06\end{array}$ & 0.60 \\
\hline $\begin{array}{l}\text { Peak aortic jet velocity, m/s } \\
\text { (per } 1 \mathrm{~m} / \mathrm{s} \text { increase) }\end{array}$ & $\begin{array}{l}1.96 \\
1.82 \text { to } 2.11\end{array}$ & $<0.001$ & - & - & $\begin{array}{l}2.50 \\
2.29 \text { to } 2.73\end{array}$ & $<0.001$ & - & - \\
\hline $\begin{array}{l}\text { Mean gradient, } \mathrm{mm} \mathrm{Hg} \\
\text { (per } 10 \mathrm{~mm} \mathrm{Hg} \text { increase) }\end{array}$ & $\begin{array}{l}1.40 \\
1.35 \text { to } 1.45\end{array}$ & $<0.001$ & $\begin{array}{l}1.48 \\
1.42 \text { to } 1.54\end{array}$ & $<0.001$ & $\begin{array}{l}1.53 \\
1.47 \text { to } 1.59\end{array}$ & $<0.001$ & $\begin{array}{l}1.54 \\
1.47 \text { to } 1.61\end{array}$ & $<0.001$ \\
\hline $\begin{array}{l}\text { Aortic valve area, } \mathrm{cm}^{2} \\
\text { (per } 0.1 \mathrm{~cm}^{2} \text { decrease) }\end{array}$ & $\begin{array}{l}1.19 \\
1.16 \text { to } 1.21\end{array}$ & $<0.001$ & - & - & $\begin{array}{l}1.24 \\
1.20 \text { to } 1.27\end{array}$ & $<0.001$ & - & - \\
\hline $\begin{array}{l}\text { Aortic valve area index, } \mathrm{cm}^{2} / \mathrm{m}^{2} \\
\text { (per } 0.1 \mathrm{~cm}^{2} / \mathrm{m}^{2} \text { decrease) }\end{array}$ & $\begin{array}{l}1.42 \\
1.36 \text { to } 1.49\end{array}$ & $<0.001$ & - & - & $\begin{array}{l}1.62 \\
1.53 \text { to } 1.72\end{array}$ & $<0.001$ & - & - \\
\hline $\begin{array}{l}\text { Energy loss index, } \mathrm{cm}^{2} / \mathrm{m}^{2} \\
\text { (per } 0.1 \mathrm{~cm}^{2} / \mathrm{m}^{2} \text { decrease) }\end{array}$ & $\begin{array}{l}1.31 \\
1.26 \text { to } 1.35\end{array}$ & $<0.001$ & - & - & $\begin{array}{l}1.46 \\
1.39 \text { to } 1.53\end{array}$ & $<0.001$ & - & - \\
\hline $\begin{array}{l}\text { Dimensionless velocity index } \\
\text { (per } 0.1 \text { decrease) }\end{array}$ & $\begin{array}{l}1.89 \\
1.74 \text { to } 2.05\end{array}$ & $<0.001$ & - & - & $\begin{array}{l}2.54 \\
2.27 \text { to } 2.83\end{array}$ & $<0.001$ & - & - \\
\hline Mitral regurgitation & $\begin{array}{l}1.15 \\
1.06 \text { to } 1.25\end{array}$ & 0.001 & $\begin{array}{l}1.06 \\
0.96 \text { to } 1.16\end{array}$ & 0.16 & $\begin{array}{l}0.96 \\
0.86 \text { to } 1.06\end{array}$ & 0.39 & - & - \\
\hline $\begin{array}{l}\text { Left ventricular ejection fraction, } \% \\
\text { (per 5\% decrease) }\end{array}$ & $\begin{array}{l}1.05 \\
1.02 \text { to } 1.07\end{array}$ & $<0.001$ & $\begin{array}{l}1.04 \\
1.01 \text { to } 1.07\end{array}$ & 0.02 & $\begin{array}{l}0.99 \\
0.95 \text { to } 1.02\end{array}$ & 0.38 & - & - \\
\hline Valvuloarterial impedance, $\mathrm{mm} \mathrm{Hg} / \mathrm{mL} \mathrm{m}^{2}$ & $\begin{array}{l}1.25 \\
1.18 \text { to } 1.33\end{array}$ & $<0.001$ & - & - & $\begin{array}{l}1.19 \\
1.11 \text { to } 1.29\end{array}$ & $<0.001$ & - & - \\
\hline
\end{tabular}


Table 3 Predictors of all-cause and cardiovascular mortality

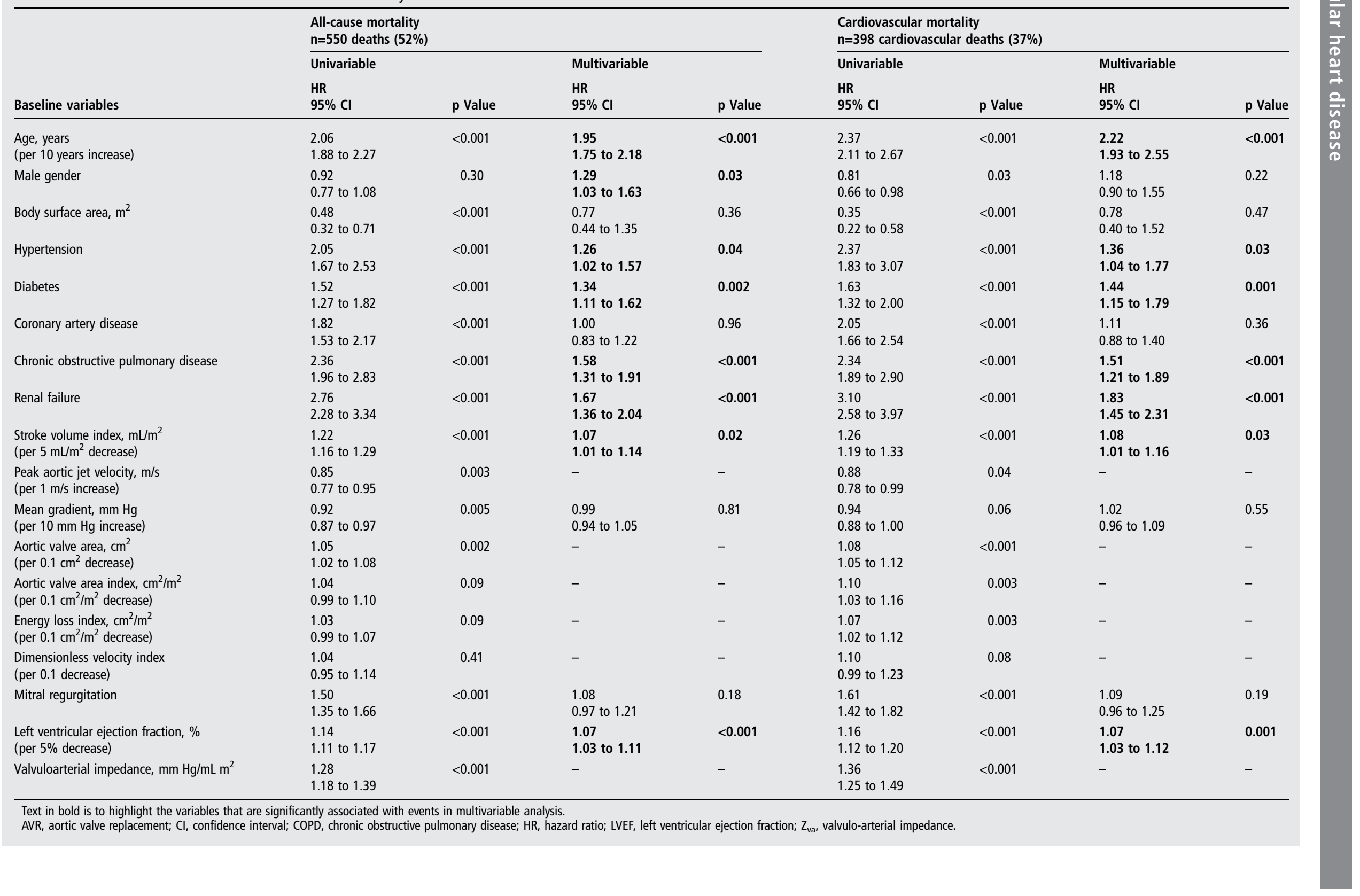




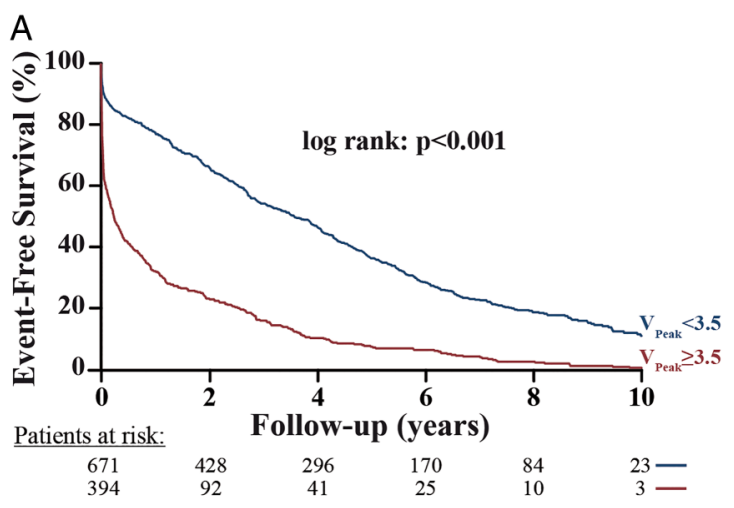

$\mathrm{B}$

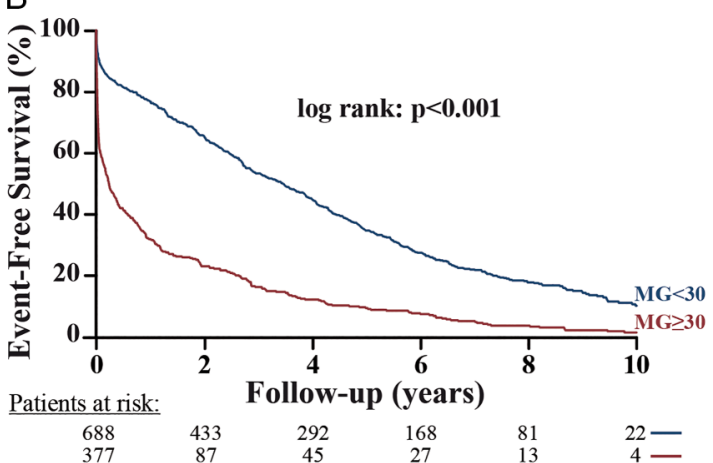

C

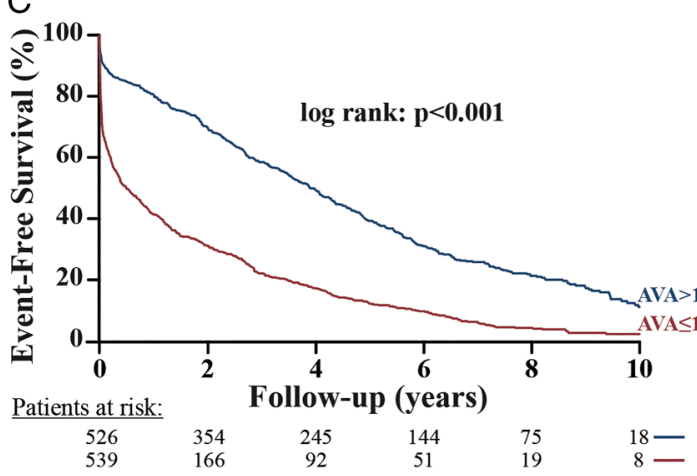

Figure 1 Event-free survival as a function of aortic stenosis severity parameters. This figure shows the event-free survival curves for the composite of aortic valve replacement or death. The groups are dichotomised according to cut-point values of peak aortic jet velocity $\left(\mathrm{V}_{\text {Peak }}\right)$, mean gradient (MG) and aortic valve area (AVA) obtained by the receiver operating characteristic curve analyses and rounded to the nearest unit or decimal: $V_{\text {Peak }} \geq$ vs $<3.5 \mathrm{~m} / \mathrm{s}(A)$; $M G \geq$ vs $<30 \mathrm{~mm} \mathrm{Hg}$ (B); $A V A \geq v s<1 \mathrm{~cm}^{2}$ (C). The numbers at the bottom of the graph represent the number of patients at risk at each follow time.

table S9). In multivariable analysis, SVi remained independently associated with all-cause mortality $(p=0.004)$, whereas LVEF was not $(p=0.56)$ (see online supplementary table S9). After the substitution of $\mathrm{SVi}$ and $\mathrm{MG}$ by $\mathrm{Z}_{\mathrm{va}}$, the latter was an independent predictor of all-cause mortality $(\mathrm{HR}=1.46$, 95\% CI 1.07 to $2.01, \mathrm{p}=0.02$ ). The results of the multivariable analysis of CV death or mortality under medical treatment in this subset of asymptomatic patients provided similar results (see online supplementary tables S9 and S10).

\section{Clinical comorbidities independently associated with all-cause mortality}

Hypertension, diabetes, coronary artery disease, chronic obstructive pulmonary disease and renal failure were all
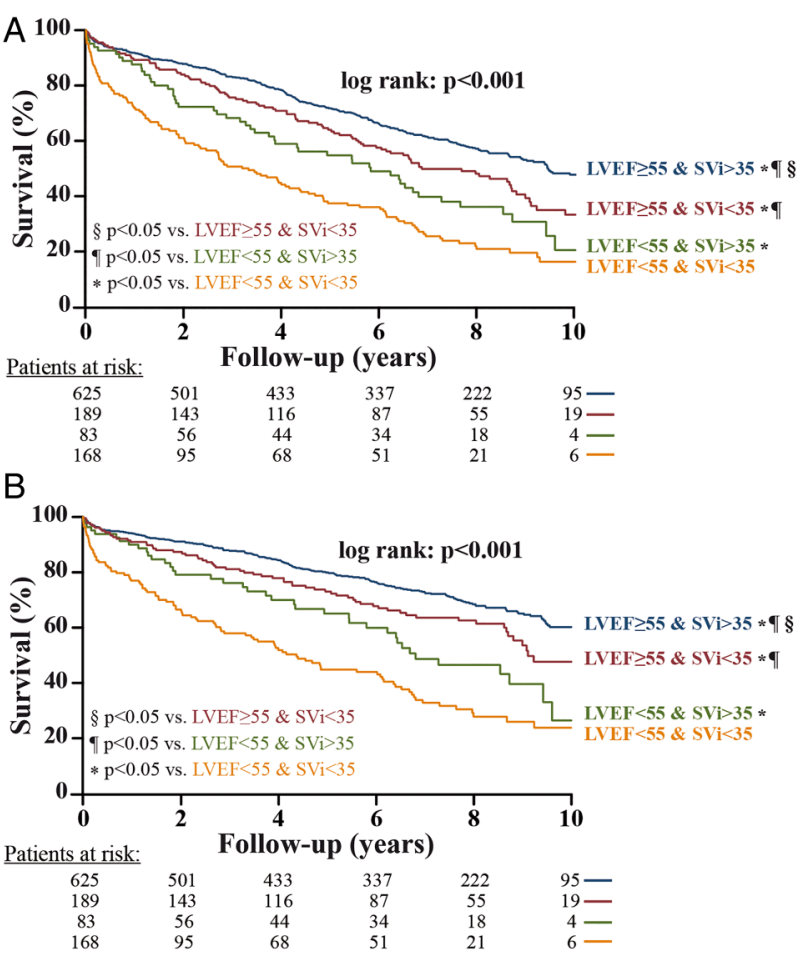

Figure 2 Overall and cardiovascular survival as a function of left ventricular ejection fraction (LVEF) and stroke volume index (SVi). This figure shows the survival curves for all-cause mortality (A) and cardiovascular mortality (B). The groups are dichotomised according to the cut-point values of LVEF and SVi obtained by the receiver operating characteristic curve analyses and rounded to the nearest unit or decimal: $\mathrm{LVEF} \geq$ vs $<55 \%$ and $\mathrm{SVi}>$ vs $<35 \mathrm{~mL} / \mathrm{m}^{2}$. The symbols indicate the significant differences between groups: ${ }^{*} p<0.05$ vs 'LVEF $<55 \%$ and SVi $<35 \mathrm{~mL} / \mathrm{m}^{2 \prime}$; ${ }^{9} \mathrm{p}<0.05$ vs 'LVEF $<55 \%$ and SVi $>35 \mathrm{~mL} / \mathrm{m}^{2 \prime} ;{ }^{\S} \mathrm{p}<0.05$ vs 'LVEF $\geq 55 \%$ and SVi $<35 \mathrm{~mL} / \mathrm{m}^{2 \prime}$. The numbers at the bottom of the graph represent the number of patients at risk at each follow time.

significantly $(\mathrm{p}<0.001)$ associated with all-cause mortality in univariable analysis (see online supplementary figure and table 3 ). After multivariable adjustment, hypertension, diabetes, chronic obstructive pulmonary disease and renal failure were independently associated with all-cause mortality, whereas coronary artery disease was not (see online supplementary figure and table 3 ).

\section{DISCUSSION}

The main findings of this study are (i) the Doppler echocardiographic parameters of stenosis severity are the most powerful predictors of the occurrence of AVR and the optimal CPVs to predict this valve-related event are lower than the criteria proposed in the guidelines for $\mathrm{V}_{\text {Peak }}$ and $\mathrm{MG}$ and similar to the guidelines' criteria for AVA; (ii) Doppler echocardiographic parameters of LV systolic/pump function, that is, low LVEF and low SVi, are the most powerful independent echocardiographic predictors of all-cause and CV mortality in patients with AS and the best CPVs to predict mortality are $\sim 55 \%$ for LVEF and $\sim 35 \mathrm{~mL} / \mathrm{m}^{2}$ for $\mathrm{SVi}$; (iii) in asymptomatic patients (ie, defined as NYHA class I), lower SVi is the most powerful echocardiographic predictor of mortality; and (iv) hypertension, diabetes, chronic obstructive pulmonary disease and renal failure, are also associated with reduced survival in the AS population. 


\section{Doppler echocardiographic parameters for grading AS severity and predicting AVR}

The AS severity criteria proposed in the guidelines are inherently inconsistent with one another. Indeed, in a patient with normal transvalvular flow rate, the MG that theoretically corresponds to an AVA value of $1.0 \mathrm{~cm}^{2}$ is closer to $30 \mathrm{~mm} \mathrm{Hg}$ rather than to the $40 \mathrm{~mm} \mathrm{Hg}$ CPV presented in the guidelines. ${ }^{10-12} \mathrm{In}$ light of these findings, some investigators have proposed to maintain the same CPV for the MG but to lower down the CPV of AVA for severe AS from 1.0 to $0.8 \mathrm{~cm}^{2} .{ }^{12}{ }^{21}$ However, the results of the present study would rather support to keep the current criteria for AVA. Indeed, the optimal CPVs of AVA $\left(\sim 1.0 \mathrm{~cm}^{2}\right)$ and indexed AVA $\left(\sim 0.55 \mathrm{~cm}^{2} / \mathrm{m}^{2}\right)$ identified in this study to predict outcomes are very close to those proposed in the guidelines, ${ }^{1}{ }^{2}$ whereas those of $\mathrm{MG}(\sim 30 \mathrm{~mm} \mathrm{Hg})$ and $\mathrm{V}_{\text {Peak }}$ $(\sim 3.5 \mathrm{~m} / \mathrm{s})$ are lower than the guidelines criteria $(40 \mathrm{~mm} \mathrm{Hg}$ and $4 \mathrm{~m} / \mathrm{s}$, respectively) (see online supplementary table S4). Hence, in light of the findings of this study, the best approach is probably to maintain the status quo with respect to the guidelines' CPVs of echocardiographic parameters and use an MG $\geq 40 \mathrm{~mm} \mathrm{Hg}$ (or $\mathrm{V}_{\text {Peak }} \geq 4.0 \mathrm{~m} / \mathrm{s}$ ) as a specific marker and an AVA $\leq 1.0 \mathrm{~cm}^{2}$ as a sensitive marker of severe stenosis (see online supplementary table $\mathrm{S} 4$ ).

If the $M G$ is $\geq 40 \mathrm{~mm} \mathrm{Hg}$ (or $V_{\text {Peak }}>4 \mathrm{~m} / \mathrm{s}$ ), the stenosis is likely severe and, in presence of symptoms, AVR is recommended (class I indication). ${ }^{1}{ }^{2}$ In these patients, it is generally not necessary to consider other parameters of stenosis severity. Nonetheless, in patients with a small ascending aorta, significant pressure recovery may occur downstream of the valve and, in such case, the MG and AVA may overestimate the stenosis severity. The calculation of the ELI may be helpful in these patients, and according to the results of this study, a value $>0.6 \mathrm{~cm}^{2} / \mathrm{m}^{2}$ (see online supplementary table S4) would indicate non-severe stenosis and good outcomes despite the presence of small AVA and high MG.

If the MG is $<40 \mathrm{~mm} \mathrm{Hg}$ and the AVA is $>1.0 \mathrm{~cm}^{2}$, the stenosis is moderate and there is no indication for AVR unless the patient undergoes another cardiac surgery. ${ }^{1}{ }^{2}$ In patients with MG $<40 \mathrm{~mm} \mathrm{Hg}$ and AVA $\leq 1.0 \mathrm{~cm}^{2}$ (ie, discordant grading) who claim to be asymptomatic or who have ambiguous symptoms, exercise testing or exercise stress echocardiography are helpful to confirm symptomatic status and corroborate stenosis severity. ${ }^{1} 219$ In patients with discordant grading and symptoms, other diagnostic tests including low-dose dobutamine stress echocardiography, and aortic valve calcium scoring by CT should be performed to confirm the stenosis severity and thus the indication of AVR. ${ }^{92} 2-25$

Asymptomatic AS is often considered a benign entity. However, in the present study, the valve event and overall mortality rates were $56 \%$ and $38 \%$, respectively, over a median follow-up of 7 years, which is consistent with what was reported in previous studies. ${ }^{6} 2627$ This relatively poor outcome may be explained by several factors: (i) patients with AS are often older and frequently have comorbidities (table 1); (ii) the stenosis may progress rapidly in an important proportion of patients and (iii) symptoms may be under-reported by the patient and/or underestimated by the physician, particularly if only a resting evaluation is used. ${ }^{242528}$

\section{Doppler echocardiographic parameters for predicting mortality}

The main goal of therapeutic management in AS is to improve longevity and quality of life, and therefore, mortality is likely the most robust and clinically relevant end point. ${ }^{29}$ Patients with advanced stage of the disease may have irreversible myocardial fibrosis/dysfunction and may thus portend increased risk of mortality despite the realisation of AVR. Furthermore, the AVR procedure per se as well as the prosthetic valve may cause several potentially life-threatening complications. An analysis including all deaths regardless of the timing of AVR is thus necessary to determine the global mortality burden associated with AS. Previous studies have generally used the composite of AVR or death as the primary and often the sole end point and, when such is the case, this composite end point was, in very large part, driven by AVR. ${ }^{3-7} 12$ Accordingly, AVR accounted for $63 \%$ of this composite end point in the present study. The main limitation of this end point is that, as opposed to death, the occurrence of AVR is, in large part, determined by the clinician's perception of disease severity, which is, in turn, highly influenced by the magnitude of $\mathrm{MG}$ or $\mathrm{V}_{\text {Peak }}$ as well as the presence of symptoms, LV systolic dysfunction (ie, LVEF <50\%) or highrisk profile (EuroSCORE $>20 \%$ ). Hence, it is not surprising that these Doppler echocardiographic parameters were found to be the most powerful independent predictors of the composite of AVR or death in this study (ie, they are the reasons why the cardiologist refers the patient to AVR). On the other hand, there was no independent association between $M G$ or $V_{\text {Peak }}$ and allcause or CV mortality in the whole cohort. Higher MG or $\mathrm{V}_{\text {Peak }}$ was nonetheless associated with increased mortality in the subset of patients treated medically but not in the subset of patients who underwent AVR. These findings further support the concept that AVR is an effective treatment for AS, and this intervention dramatically changes the natural history of the disease. It is reassuring to see that in a contemporary 'real-life' series of patients with optimised management there is no death penalty associated with severe AS. The Doppler echocardiographic parameters independently associated with mortality were those of LV systolic/pump function: that is, LVEF and SVi. Furthermore, the best CPV for LVEF to predict 1-year mortality was $\sim 55 \%$, which is higher than the CPV proposed in the guidelines $(<50 \%)$ to identify the presence of LV systolic dysfunction and recommend AVR in symptomatic severe AS patients (class I). This finding may be explained by the fact that LVEF substantially underestimates the degree of myocardial systolic dysfunction in the presence of LV concentric remodelling as is often the case in patients with AS. ${ }^{30-33}$ Previous studies reported that about one-third of patients with severe AS and LVEF $\geq 50 \%$ have evidence of LV systolic dysfunction as documented by reduced LV longitudinal or mid-wall shortening. ${ }^{34-37}$ The results of the present study suggest that the CPV of LVEF proposed in the guidelines to identify LV systolic dysfunction, and thus trigger AVR in patients with severe AS could be raised from $50 \%$ to $55 \%$. Another important finding of this study is that SVi provides important incremental prognostic value in both patients with preserved LVEF and those with reduced LVEF. Several studies including a recent meta-analysis have reported that low flow, that is, reduced SVi, is associated with worse prognosis in patients with preserved LVEF. ${ }^{13-16} 38-42$ The present study also shows that SVi is a powerful predictor of mortality among patients with reduced LVEF. The primary function of the heart is to pump blood into the systemic circulation and it thus appears logical to use the SVi as the key parameter to measure the efficiency of the LV pump. Furthermore, this parameter is routinely measured in the echocardiography or catheterisation laboratories for the calculation of cardiac output and AVA and it is thus easily available. The results of the present study further validate the cut-point of $35 \mathrm{~mL} / \mathrm{m}^{2}$ proposed by 
Hachicha $e t a l^{13}$ and recently reported by the guidelines ${ }^{12}$ to define low flow and predict adverse outcomes in AS.

The contemporary AS population is composed predominantly of elderly people with frequent comorbidities (hypertension, coronary artery disease, diabetes, atrial fibrillation) that may, besides AS, all contribute to decrease LV outflow. ${ }^{13} 15 \quad 3941$ Hence, as reported in previous studies, ${ }^{11} 134043$ it is not surprising that a large proportion of patients with AS have reduced SVi (34\% in the present study) and given that MG and $\mathrm{V}_{\text {Peak }}$ are highly flow dependent, these parameters may result in underestimation of stenosis severity and risk of events. This further emphasises the importance of (i) considering both LVEF and SVi in the risk stratification process of patients with AS and (ii) not relying only on $M G$ and $V_{\text {Peak }}$ to grade AS severity. Furthermore, even if low LVEF and low SVi may be used to identify patients with AS being at higher risk for cardiac events, the identification of the underlying cause(s) of impaired LV systolic/pump function may help to adjust therapeutic management.

\section{STUDY LIMITATIONS}

The main limitation of the present work is that the data were prospectively collected but retrospectively queried. Hence, this study has the inherent limitation of a retrospective analysis. However, the fact that we included a large series of consecutive patients examined at the clinical Echocardiography Laboratory and that the mortality data were obtained from the Quebec National Institute of Statistics limited the selection and follow-up biases.

The present study confirms the usefulness of SVi and AVA measured by Doppler echocardiography to predict outcomes in patients with AS. However, these parameters are subject to measurement errors and a multimodality, multiparametric integrative approach should be used to corroborate these measurements. However, special attention should be taken when using hybrid method, such as CT-echo hybrid method, to determine AS severity: as recently reported, CPV of AVA to predict mortality was $1 \mathrm{~cm}^{2}$ when derived from echocardiography but $1.2 \mathrm{~cm}^{2}$ when derived from CT-echo hybrid method. ${ }^{44}$ This raises the need of identification and validation of specific CPV values to predict outcomes for every imaging modalities.

Even if the complementary analyses in specific subsets of patients provided consistent results with those in the whole cohort, some of these subanalyses may be underpowered. Moreover, the multiple analyses performed in this study may increase the risk of type I error. These findings will thus need to be further validated in larger studies.

The data of the extent of coronary artery disease, myocardial strain or wall motion abnormalities, as well as dobutamine stress echocardiography were not available in this cohort. Moreover, the complete list of medications has not been collected.

\section{CONCLUSION}

The Doppler echocardiographic parameters of stenosis severity, that is, MG, $\mathrm{V}_{\text {Peak }}$ and AVA, are the most powerful predictors of the need for AVR. However, the optimal CPVs to predict this event are lower than the criteria proposed in the guidelines for $\mathrm{V}_{\text {Peak }}$ and $M G$, whereas they are similar for AVA. These findings thus support the status quo for the CPV of AVA $\left(\leq 1.0 \mathrm{~cm}^{2}\right)$ to identify severe AS. The most powerful predictors of all-cause and $\mathrm{CV}$ mortality are parameters of LV systolic/pump function: that is, LVEF and SVi. However, the results of this study suggest that the CPV of LVEF to identify LV systolic dysfunction and trigger AVR in AS may be raised from $50 \%$ to $55 \%$. This finding will need to be confirmed by further studies. The presence of low flow, defined as SVi $<35 \mathrm{~mL} / \mathrm{m}^{2}$, should be systematically integrated, complementary to LVEF, in the risk stratification of both asymptomatic and symptomatic patients with AS.

\section{Key messages}

\section{What is already known on this subject?}

A significant proportion of patients with aortic stenosis (AS) may present with discrepancies among echocardiographic parameters for the grading of stenosis severity: that is, mean gradient $<40 \mathrm{~mm} \mathrm{Hg}$ but aortic valve area (AVA) $<1 \mathrm{~cm}^{2}$. Some investigators thus proposed to lower the severity cut-point value of AVA down to $0.8 \mathrm{~cm}^{2}$. Left ventricular ejection fraction (LVEF) $<50 \%$ is the parameter proposed in the guidelines to define LV systolic dysfunction and recommend aortic valve replacement in AS. However, this parameter may lack sensitivity.

\section{What might this study add?}

This study confirms that the optimal cut-point value of AVA to define severe AS is $<1.0 \mathrm{~cm}^{2}$ and does not support the lowering to $0.8 \mathrm{~cm}^{2}$. The most powerful echocardiographic predictors of mortality were the presence of low LV outflow defined as a stroke volume index $<35 \mathrm{~mL} / \mathrm{m}^{2}$ and low LVEF $(<55 \%)$.

\section{How might this impact on clinical practice?}

The findings of this study support (i) the status quo regarding the guidelines' criteria for severe AS: a mean gradient $\geq 40 \mathrm{~mm} \mathrm{Hg}$ and AVA $\leq 1.0 \mathrm{~cm}^{2}$ may be used as a specific and sensitive marker of stenosis severity, respectively; (ii) the raise of the cut-point value of LVEF to identify LV systolic dysfunction in AS from $50 \%$ to $55 \%$ and (iii) the systematic integration of stroke volume index in the risk stratification of AS.

Acknowledgements The authors thank Isabelle Fortin, Jocelyn Beauchemin, Martine Poulin and Martine Parent for their help in data collection and management.

Contributors $\mathrm{RC}$ and PP designed the study and prepared the manuscript. RC, FLV and M-AC collected data. RC, FLV, M-AC, JGD, AD, CT, MA, KOC, EB, JB, MS and $\mathrm{MB}$ contributed to the analysis of echocardiographic measures and interpretation of the data. RC performed statistical analyses and wrote the first draft of the manuscript. PP supervised the acquisition and analyses of echocardiographic images. All authors reviewed the manuscript and contributed to scientific content. PP validated the final version and are responsible for the overall content.

Funding This work was supported by grant MOP-114997 from Canadian Institutes of Health Research (CIHR), Ottawa, Ontario, Canada, and a grant from the Foundation of the Québec Heart and Lung Institute. RC was supported by a post-doctoral fellowship grant from CIHR. FLV and CT were supported by a clinical and research fellowship grant from Fédération Française de Cardiologie. M-AC was supported by a post-doctoral fellowship grant from CIHR. AD was supported by a fellowship grant from L'Agence de la santé et des services sociaux de la Capitale Nationale, Québec, Québec, Canada. MA is research scholars from 'Fond de Recherche en Santé du Québec (FRSQ), Montreal, Québec, Canada. PP holds the Canada Research Chair in Valvular Heart Diseases from CIHR, Ottawa, Ontario, Canada.

Competing interests None.

Patient consent Written informed consent was waived for this retrospective analysis.

Ethics approval The study was approved by the Ethics Committee of the Quebec Heart and Lung Institute.

Provenance and peer review Not commissioned; externally peer reviewed.

\section{REFERENCES}

1 Vahanian A, Alfieri O, Andreotti F, et al., Joint Task Force on the Management of Valvular Heart Disease of the European Society of Cardiology (ESC); European 
Association for Cardio-Thoracic Surgery (EACTS). Guidelines on the management of valvular heart disease (version 2012). Eur Heart J 2012;33:2451-96.

2 Nishimura RA, Otto CM, Bonow RO, et al. 2014 AHA/ACC guideline for the management of patients with valvular heart disease: a report of the American College of Cardiology/American Heart Association Task Force on Practice Guidelines. J Am Coll Cardiol 2014;63:e57-185.

3 Otto CM, Burwash IG, Legget ME, et al. Prospective study of asymptomatic valvular aortic stenosis: clinical, echocardiographic, and exercise predictors of outcome. Circulation 1997;95:2262-70.

4 Rosenhek R, Binder T, Porenta G, et al. Predictors of outcome in severe, asymptomatic aortic stenosis. N Engl J Med 2000;343:611-17.

5 Rosenhek R, Klaar U, Schemper M, et al. Mild and moderate aortic stenosis. Natural history and risk stratification by echocardiography. Eur Heart $J$ 2004;25:199-205.

6 Pellikka PA, Sarano ME, Nishimura RA, et al. Outcome of 622 adults with asymptomatic, hemodynamically significant aortic stenosis during prolonged follow-up. Circulation 2005;111:3290-5.

7 Rosenhek R, Zilberszac R, Schemper M, et al. Natural history of very severe aortic stenosis. Circulation 2010;121:151-6.

8 Malouf J, Le Tourneau T, Pellikka P, et al. Aortic valve stenosis in community medical practice: Determinants of outcome and implications for aortic valve replacement. J Thorac Cardiovasc Surg 2012;144:1421-7.

9 Pibarot P, Dumesnil JG. Low-flow, low-gradient aortic stenosis with normal and depressed left ventricular ejection fraction. J Am Coll Cardiol 2012;60:1845-53.

10 Carabello BA. Clinical practice. Aortic stenosis. N Engl J Med 2002;346:677-82.

11 Minners J, Allgeier M, Gohlke-Baerwolf C, et al. Inconsistent grading of aortic valve stenosis by current guidelines: haemodynamic studies in patients with apparently normal left ventricular function. Heart 2010;96:1463-8.

12 Jander N, Minners J, Holme I, et al. Outcome of patients with low-gradient "severe" aortic stenosis and preserved ejection fraction. Circulation 2011;123:887-95.

13 Hachicha Z, Dumesnil JG, Bogaty P, et al. Paradoxical low-flow, low-gradient severe aortic stenosis despite preserved ejection fraction is associated with higher afterload and reduced survival. Circulation 2007;115:2856-64.

14 Lancellotti P, Magne J, Donal E, et al. Clinical outcome in asymptomatic severe aortic stenosis: insights from the new proposed aortic stenosis grading classification. J Am Coll Cardiol 2012;59:235-43.

15 Clavel MA, Dumesnil JG, Capoulade R, et al. Outcome of patients with aortic stenosis, small valve area and low-flow, low-gradient despite preserved left ventricular ejection fraction. J Am Coll Cardiol 2012;60:1259-67.

16 Dayan V, Vignolo G, Magne J, et al. Outcome and Impact of Aortic Valve Replacement in Patients With Preserved LVEF and Low-Gradient Aortic Stenosis. J Am Coll Cardiol 2015;66:2594-603.

17 Hachicha Z, Dumesnil JG, Pibarot P. Usefulness of the valvuloarterial impedance to predict adverse outcome in asymptomatic aortic stenosis. J Am Coll Cardiol 2009;54:1003-11.

18 Garcia D, Pibarot P, Dumesnil JG, et al. Assessment of aortic valve stenosis severity: a new index based on the energy loss concept. Circulation 2000;101:765-71.

19 Baumgartner $\mathrm{H}$, Hung J, Bermejo J, et al. Echocardiographic assessment of valve stenosis: EAE/ASE recommendations for clinical practice. J Am Soc Echocardiogr 2009;22:1-23.

20 Lancellotti P, Tribouilloy C, Hagendorff A, et al. Recommendations for the echocardiographic assessment of native valvular regurgitation: an executive summary from the European Association of Cardiovascular Imaging. Eur Heart J Cardiovasc Imaging 2013;14:611-44.

21 Zoghbi WA. Low-gradient "severe" aortic stenosis with normal systolic function: time to refine the guidelines? Circulation 2011;123:838-40.

22 Clavel MA, Ennezat PV, Marchaux S, et al. Stress echocardiography to assess stenosis severity and predict outcome in patients with paradoxical low-flow, low-gradient aortic stenosis and preserved LVEF. J Am Coll Cardiol Img 2013;6:175-83.

23 Clavel MA, Messika-Zeitoun D, Pibarot $P$, et al. The complex nature of discordant severe calcified aortic valve disease grading: new insights from combined
Doppler-echocardiographic and computed tomographic study. J Am Coll Cardiol 2013:62:2329-38.

24 Lancellotti $\mathrm{P}$, Lebois $\mathrm{F}$, Simon $\mathrm{M}$, et al. Prognostic importance of quantitative exercise Doppler echocardiography in asymptomatic valvular aortic stenosis. Circulation 2005;112:1377-182.

25 Maréchaux S, Hachicha Z, Bellouin A, et al. Usefulness of exercise stress echocardiography for risk stratification of true asymptomatic patients with aortic valve stenosis. Eur Heart J 2010;31:1390-7.

26 Otto CM, Lind BK, Kitzman DW, et al. Association of aortic-valve sclerosis with cardiovascular mortality and morbidity in the elderly. $N$ Engl J Med 1999:341:142-7.

27 Clavel MA, Malouf J, Michelena HI, et al. B-type natriuretic peptide clinical activation in aortic stenosis: Impact on long-term survival. J Am Coll Cardiol 2014;63:2016-25.

28 Capoulade R, Magne J, Dulgheru R, et al. Prognostic value of plasma B-type natriuretic peptide levels after exercise in patients with severe asymptomatic aortic stenosis. Heart 2014;100:1606-12.

29 Lauer MS, Blackstone EH, Young JB, et al. Cause of death in clinical research: time for a reassessment? J Am Coll Cardiol 1999;34:618-20.

30 Dumesnil JG, Shoucri RM. Effect of the geometry of the left ventricle on the calculation of ejection fraction. Circulation 1982;65:91-8.

31 Cramariuc D, Gerdts E, Davidsen ES, et al. Myocardial deformation in aortic valve stenosis: relation to left ventricular geometry. Heart 2010;96:106-12.

32 Lancellotti P, Donal E, Magne J, et al. Risk stratification in asymptomatic moderate to severe aortic stenosis: the importance of the valvular, arterial and ventricular interplay. Heart 2010;96:1364-71.

33 Capoulade R, Larose E, Mathieu P, et al. Visceral adiposity and left ventricular mass and function in patients with aortic stenosis: The PROGRESSA study. Can J Cardiol 2014;30:1080-7

34 Cramariuc D, Cioffi G, Rieck $A E$, et al. Low-flow aortic stenosis in asymptomatic patients: Valvular arterial impedance and systolic function from the SEAS substudy. JAmCollCardiollmg 2009;2:390-9.

35 Delgado V, Tops LF, van Bommel RJ, et al. Strain analysis in patients with severe aortic stenosis and preserved left ventricular ejection fraction undergoing surgical valve replacement. Eur Heart J 2009;30:3037-47.

$36 \mathrm{Ng} \mathrm{AC}$, Delgado V, Bertini M, et al. Alterations in multidirectional myocardial functions in patients with aortic stenosis and preserved ejection fraction: a two-dimensional speckle tracking analysis. Eur Heart J 2011;32:1542-50.

37 Yingchoncharoen T, Gibby C, Rodriguez LL, et al. Association of myocardial deformation with outcome in asymptomatic aortic stenosis with normal ejection fraction. Circ Cardiovasc Imaging 2012;5:719-25.

38 Barasch E, Fan D, Chukwu EO, et al. Severe isolated aortic stenosis with normal left ventricular systolic function and low transvalvular gradients: pathophysiologic and prognostic insights. J Heart Valve Dis 2008;17:81-8.

39 Mehrotra P, Jansen K, Flynn AW, et al. Differential left ventricular remodelling and longitudinal function distinguishes low flow from normal-flow preserved ejection fraction low-gradient severe aortic stenosis. Eur Heart J 2013;34:1906-14.

40 Mohty D, Magne J, Deltreuil M, et al. Outcome and impact of surgery in paradoxical low-flow, low-gradient severe aortic stenosis and preserved left ventricular ejection fraction: A cardiac catheterization study. Circulation 2013;128: S235-S42.

41 Eleid MF, Sorajja P, Michelena HI, et al. Flow-gradient patterns in severe aortic stenosis with preserved ejection fraction: clinical characteristics and predictors of survival. Circulation 2013;128:1781-9.

42 Eleid MF, Sorajja P, Michelena HI, et al. Survival by stroke volume index in patients with low-gradient normal EF severe aortic stenosis. Heart 2015;101:23-9.

43 Herrmann HC, Pibarot P, Hueter I, et al. Predictors of mortality and outcomes of therapy in low-flow severe aortic stenosis: a Placement of Aortic Transcatheter Valves (PARTNER) trial analysis. Circulation 2013;127:2316-26.

44 Clavel MA, Malouf J, Messika-Zeitoun D, et al. Aortic valve area calculation in aortic stenosis by CT and doppler echocardiography. JACC Cardiovasc Imaging 2015;8:248-57. 